\title{
Repair of posterior mitral valve prolapse with a novel leaflet plication clip in an animal model
}

\author{
Eric N. Feins, MD, ${ }^{a}$ Haruo Yamauchi, MD, PhD, ${ }^{a}$ Gerald R. Marx, MD, ${ }^{b}$ Franz P. Freudenthal, MD, \\ Hua Liu, MS, ${ }^{a}$ Pedro J. del Nido, MD, ${ }^{a}$ and Nikolay V. Vasilyev, MD $^{\mathrm{a}}$
}

\begin{abstract}
Objective: Recently, there has been increased interest in minimally invasive mitral valve prolapse repair techniques; however, these techniques have limitations. A new technique was developed for treating mitral valve prolapse that uses a novel leaflet plication clip to selectively plicate the prolapsed leaflet segment. The clip's efficacy was tested in an animal model.
\end{abstract}

\begin{abstract}
Methods: Yorkshire pigs $(n=7)$ were placed on cardiopulmonary bypass $(\mathrm{CPB})$, and mitral valve prolapse was created by cutting chordae supporting the $\mathrm{P} 2$ segment of the posterior leaflet. Animals were weaned off $\mathrm{CPB}$ and mitral regurgitation (MR) was assessed echocardiographically. CPB was reinitiated and the plication clip was applied under direct vision to the P2 segment to eliminate the prolapse. The animals survived for 2 hours. Epicardial echocardiography was obtained before and after prolapse creation and 2 hours after clip placement to quantify MR grade and vena contracta area. Posterior leaflet mobility and coaptation height were analyzed before and after clip placement.
\end{abstract}

Results: There were no cases of clip embolization. Median MR grade increased from trivial (0-1.5) to moderatesevere after MR creation $(2.5-4+)(P<.05)$, and decreased to mild after clip placement $(0-3+)(P<.05)$. Vena contracta area tended to increase after cutting the chordae and decrease after clip placement: $0.08 \pm 0.10 \mathrm{~cm}^{2}$ versus $0.21 \pm 0.15 \mathrm{~cm}^{2}$ versus $0.16 \pm 0.16 \mathrm{~cm}^{2}(P=.21)$. The plication clip did not impair leaflet mobility. Coaptation height was restored to baseline: $0.51 \pm 0.07 \mathrm{~cm}$ versus $0.44 \pm 0.18 \mathrm{~cm}(P=1.0)$.

Conclusions: The leaflet plication clip can treat mitral valve prolapse in an animal model, restoring coaptation height without affecting leaflet mobility. This approach is a simple technique that may improve the effectiveness of beating-heart and minimally invasive valve surgery. (J Thorac Cardiovasc Surg 2014;147:783-91)

Video clip is available online.

Mitral regurgitation (MR) is one of the leading valverelated indications for cardiac surgery, with degenerative mitral valve disease being the predominant pathology. ${ }^{1}$

From the Departments of Cardiac Surgery ${ }^{\mathrm{a}}$ and Cardiology, ${ }^{\mathrm{b}}$ Boston Children's Hospital, Harvard Medical School, Boston, Mass; and Department of Pediatric Cardiology, ${ }^{\mathrm{c}}$ Kardiozentrum, La Paz, Bolivia.

The work was support by the National Heart, Lung and Blood Institute (NIH) Award No. 5R01HL073647: "Image-guided Intracardiac Beating-Heart Surgery" (P.J.d.N.). The equipment and technology used in the study were purchased using academic funds.

Disclosures: Franz Freudenthal is employed by PFM Bolivia, the manufacturer of the device prototype. The authors had full control of the design of the studies, methods used, outcome measurements, analysis of data, and production of the written report. All other authors have nothing to disclose with regard to commercial support.

Read at the 93rd Annual Meeting of The American Association for Thoracic Surgery, Minneapolis, Minnesota, May 4-8, 2013.

Received for publication May 5, 2013; revisions received Sept 12, 2013; accepted for publication Sept 19, 2013; available ahead of print Nov 11, 2013.

Address for reprints: Nikolay V. Vasilyev, MD, Department of Cardiac Surgery, Boston Children's Hospital, Harvard Medical School, 300 Longwood Ave, Boston, MA 02115 (E-mail: nikolay.vasilyev@ childrens.harvard.edu).

$0022-5223 / \$ 36.00$

Copyright (C) 2014 by The American Association for Thoracic Surgery

http://dx.doi.org/10.1016/j.jtcvs.2013.09.044
Prolapse of the middle scallop of the posterior leaflet (P2) caused by chordal elongation or rupture is the most common lesion seen in degenerative mitral valve disease. ${ }^{2}$ The conventional surgical technique for repair of mitral valve prolapse (MVP) involves resection of the prolapsed posterior leaflet segment along with a mitral annuloplasty, as described by Carpentier. ${ }^{3}$ In addition, folding valvuloplasty techniques have recently been revisited and are viewed by some as a preferred method of MVP repair, particularly in the setting of minimally invasive mitral valve surgery. ${ }^{4-7}$ Surgical repair of MVP is effective, durable, and safe: 10 -year freedom from reoperation exceeds $90 \%$ and perioperative mortality approximates $0.5 \%{ }^{8,9}$ However, there are patients who are not candidates for conventional heart surgery and cardiopulmonary bypass $(\mathrm{CPB}) .{ }^{10-13}$ For this cohort, minimally invasive and beating-heart mitral valve repair techniques and devices have an important role, offering the opportunity for valve repair while avoiding the potential risks associated with heart surgery and CPB. Emerging devices address the components of the mitral apparatus, including the leaflets, annulus, and chordae tendineae. ${ }^{14}$ Most notable is the MitraClip (Abbott Vascular, Inc, Menlo Park, Calif), a transcatheter device that treats MR by mimicking a surgical edge-to-edge repair. Although the MitraClip has been one of the most 


$$
\begin{aligned}
& \text { Abbreviations and Acronyms } \\
& \begin{aligned}
\text { ANOVA }=\text { analysis of variance } \\
\text { CH }=\text { coaptation height } \\
\text { CPB }=\text { cardiopulmonary bypass } \\
\text { IACUC }=\text { Institutional Animal Care and Use } \\
\\
\text { Committee } \\
\text { ICC }=\text { intraclass correlation coefficients } \\
\text { LPC }=\text { leaflet plication clip } \\
\text { MVP }=\text { mitral valve prolapse } \\
\text { VCA }=\text { vena contract area }
\end{aligned}
\end{aligned}
$$

extensively tested and used devices, this technology has been used predominantly in patients with ischemic MR. Therefore, there remains a need for alternative mitral valve repair devices to address myxomatous mitral valve disease and expand the versatility and effectiveness of minimally invasive and beating-heart mitral valve surgery.

In an effort to answer this unmet need, a new technique of leaflet plication was developed that uses a novel leaflet plication clip (LPC) to treat MVP. The LPC folds (or plicates) the prolapsed leaflet segment without involving the neighboring leaflet segments or the anterior leaflet. Although the ultimate goal is to implant the LPC in minimally invasive procedures, including image-guided beating-heart techniques, the aim of the present study was to test the clip's performance and short-term efficacy for treating MVP using open surgery in an animal model.

\section{MATERIALS AND METHODS Device Overview}

The LPC is composed of a folded nickel-titanium alloy (nitinol) wire that is $0.45 \mathrm{~mm}$ in diameter. The device has a central loop and 2 sharpened ends distally (Figure 1, $A$ ). It has a closed resting state and can be opened to expose the sharpened tips and incorporate the entire prolapsed leaflet segment during implantation (Figure $1, B$ and $C$ ). For the current study, the clip measuring $11 \mathrm{~mm}$ in length and $3 \mathrm{~mm}$ in width in its resting state was used in all cases, except 1 where a larger clip was used. In its open state, the clip tips are approximately $6 \mathrm{~mm}$ apart, which defines the amount of leaflet tissue that is plicated. Clips can be manufactured in a range of sizes to plicate varying amounts of tissue. A specialized, hand-held deployment device was developed that engages the LPC and can open/ close the device for implantation (Figure $1, D$ ).

Device implantation involves the following steps (Figure 2, Video 1):

1. Open the LPC, which is mounted on the tip of the deployment device (Figure 1, D, arrow).

2. Direct the distal clip arms toward the belly of the prolapsed leaflet segment with the device oriented perpendicular to the leaflet hinge point.

3. Puncture the prolapsed segment midway between the leaflet hinge point and the free edge.

4. Advance the LPC until the proximal elbow abuts the leaflet tissue.

5. Close the LPC, which folds/plicates the involved leaflet tissue into the device.

6. Disengage the LPC from the deployment device. The clip remains in its closed state due to the shape memory of the nitinol material.
The clip that was used in this study does not involve the annular tissue. It solely plicates the leaflet tissue between the midbelly and the free edge of the leaflet. This positioning allows for leaflet plication without affecting annular geometry. Notably, the LPC can be removed and reinserted without causing significant leaflet trauma, thus allowing for repositioning in cases of suboptimal clip implantation.

\section{Investigational Protocol}

The experimental protocol was approved by the Boston Children's Hospital Institutional Animal Care and Use Committee (IACUC). All animals received humane care in accordance with the 1996 Guide for the Care and Use of Laboratory Animals recommended by the US National Institutes of Health.

Yorkshire female pigs $(60-73 \mathrm{~kg}, \mathrm{n}=7)$ were anesthetized using intramuscular injection of telazol $(4.4 \mathrm{mg} / \mathrm{kg})$, xylazine $(2.2 \mathrm{mg} / \mathrm{kg})$, and atropine $(0.04 \mathrm{mg} / \mathrm{kg})$, and then intubated with a cuffed endotracheal tube and ventilated with a volume-control ventilator (Fabius Tiro; Draeger Medical, Andover, Mass). Anesthesia was maintained with inhaled desflurane $(4 \%-9 \%)$. A transurethral urinary catheter was inserted for monitoring of urine output. Arterial and central venous lines were placed percutaneously in the left femoral artery and vein for arterial and central venous pressure monitoring, respectively. Electrocardiography and temperature monitoring were accomplished via esophageal and rectal probes, respectively. A right groin incision was made and the right femoral artery was exposed for arterial cannulation. After administration of intravenous cisatrocurium $(0.1 \mathrm{mg} / \mathrm{kg})$, a left posterolateral thoracotomy was performed through the fourth intercostal space. Stay sutures were placed in the pericardium to optimize access to the left atrial appendage, and a baseline two-dimensional (2D) and three-dimensional (3D) epicardial echocardiogram was performed. After intravenous heparin administration $(300 \mathrm{U} / \mathrm{kg})$ to achieve an activated clotting time of $>350$ seconds, arterial cannulation was performed via the right femoral artery using an $18 \mathrm{~F}$ cannula. Venous cannulation was achieved via the right atrial appendage with a $34 \mathrm{~F}$ straight, single-stage cannula. CPB was initiated using an oxygenator (FX25; Terumo Medical Corporation, Somerset, NJ). Fentanyl (50-200 $\mu / \mathrm{kg})$ and midazolam $(0.2 \mathrm{mg} / \mathrm{kg}$ ) were administered for anesthesia during $\mathrm{CPB}$. The animals were cooled to $32^{\circ} \mathrm{C}$, at which point the ascending aorta was crossclamped and cold cardioplegia solution (del Nido cardioplegia solution) was delivered in an anterograde fashion via the aortic root. ${ }^{15}$ After cardiac arrest, the left atrial appendage was opened and suspended upward with stay sutures to expose the mitral valve. Valve competence was assessed by cold saline injection. Then primary marginal and secondary chordae tendineae supporting the P2 segment of the posterior mitral leaflet were cut, mimicking chordal rupture and MVP/flail. MVP was confirmed with repeat cold saline injection, after which the left atrial appendage was closed. The animals were rewarmed, the heart was deaired, and the aortic crossclamp was removed. After weaning off CPB, repeat 2D/3D epicardial echocardiography was performed to document valve function. The animals were then placed back on CPB and cooled to $32^{\circ} \mathrm{C}$. The ascending aorta was again crossclamped and the heart was arrested in the same manner as before. The left atrial appendage was reopened, and after examining the prolapsed P2 segment, the LPC was applied under direct vision to repair the prolapse. Repeat cold saline injection was administered to assess device position and valve competence. The left atriotomy was then closed and the animals were rewarmed. After deairing, the aortic crossclamp was removed, the animals were weaned off $\mathrm{CPB}$, and the cannulae were removed. 2D/3D epicardial echocardiography was repeated 2 hours after discontinuing CPB. The animals were then euthanized by intravenous injection of overdosed pentobarbital sodium (Fatal-Plus; Vortech Pharmaceuticals, Dearborn, Mich; 86 $\mathrm{mg} / \mathrm{kg}$ ). The heart was then excised and opened for direct inspection.

\section{Echocardiographic Measurement and Analysis}

Epicardial 2D and 3D echocardiograms were obtained at 3 time points: (1) before MVP creation, (2) after MVP creation, and (3) 2 hours after clip 


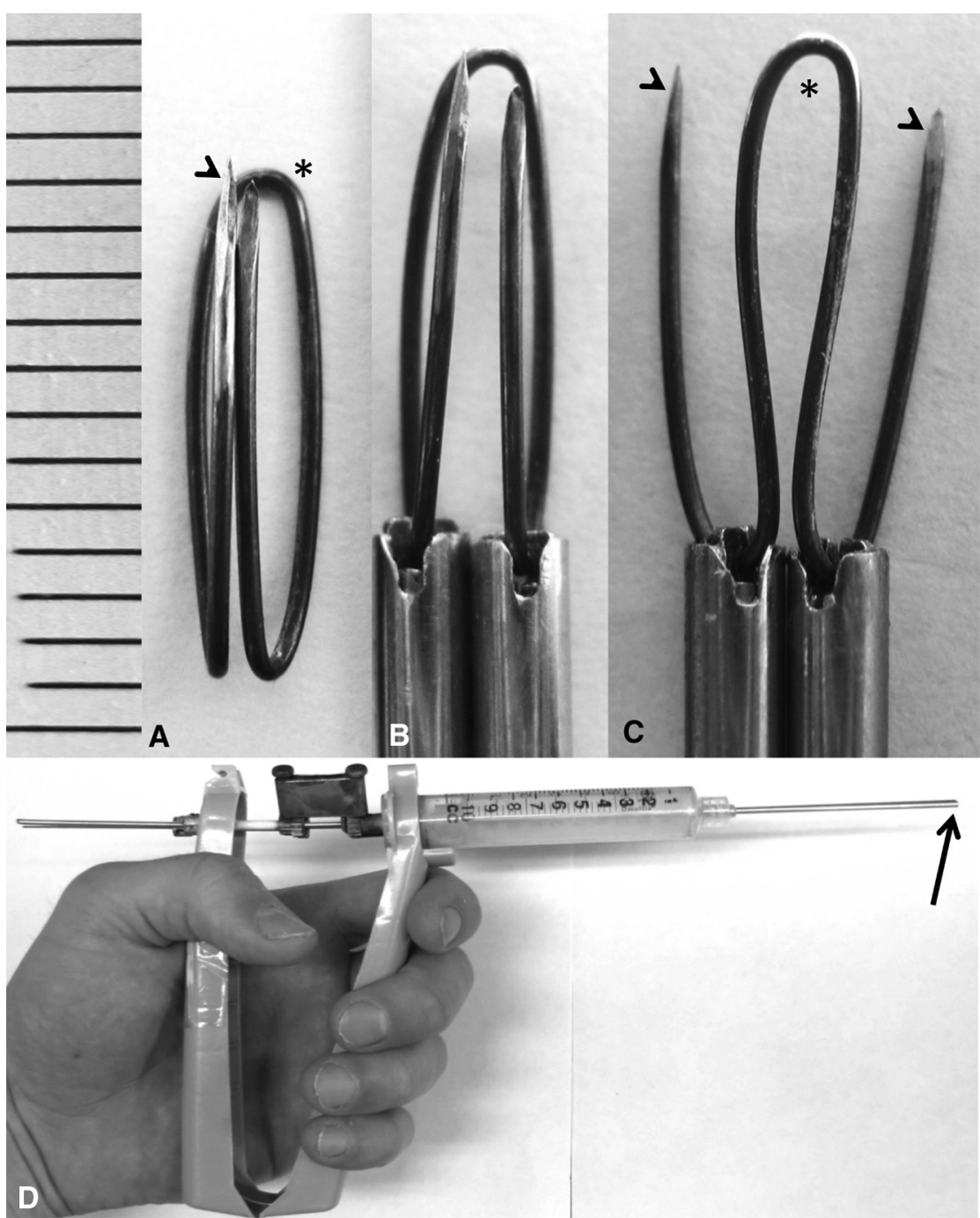

FIGURE 1. Leaflet plication clip and deployment device. A, Resting state of leaflet plication clip. B, Leaflet plication clip mounted on the deployment device in closed/resting state. C, Leaflet plication clip in open state. D, Deployment device; leaflet plication clip mounts on its tip. Asterisk indicates the central loop of the leaflet plication clip; the arrowhead indicates the sharpened arms of the leaflet plication clip; the arrow indicates the tip of the deployment device where the clip is mounted. The ruler indicates 1-mm marks.

implantation. All echocardiograms were obtained with animals completely off CPB using a matrix array probe X7-2 (2-7 MHz) on an iE33 system (Philips Healthcare, Andover, Mass). Echocardiographic imaging was analyzed by 2 investigators who were blinded to animal and time point identification.

The severity of MR was graded according to the extent of the color Doppler regurgitant jet visualized on 2D color Doppler imaging. MR grade was categorized as none $(0)$, trivial $(1+)$, mild $(2+)$, moderate $(3+)$, or severe $(4+)$. Intermediate gradings were defined by intervals of 0.5 (eg, $2.5=$ mild to moderate). Color Doppler and noncolor 3D images were acquired in the full-volume acquisition mode and then analyzed offline using the multiplanar 3D quantification mode in Qlab software, Version 8.1 (Philips Healthcare, Andover, Mass). Vena contract area (VCA) of the MR jet was measured before MR creation, after MR creation, and 2 hours after device implantation. VCA was measured at the frame in systole where MR was felt to be the greatest, as described elsewhere. ${ }^{16}$

Coaptation height $(\mathrm{CH})$ was analyzed in cases where an optimal functional result was obtained with the LPC. The purpose of this analysis was to determine whether normal $\mathrm{CH}$ could be restored by the clip in cases of device success. $\mathrm{CH}$ was analyzed at midsystole by obtaining a cross-sectional plane through the A2-P2 region of the mitral valve, and then measuring the height of leaflet coaptation (Figure 3, A).

Posterior mitral leaflet mobility was analyzed to assess whether the LPC restricted posterior leaflet motion and impaired valve function. To assess leaflet mobility, the posterior leaflet was examined in a cross-sectional plane through the $\mathrm{P} 2$ segment. At midsystole, the angle between the mitral annular plane and the plane through the belly of $\mathrm{P} 2$ was determined $\left(\theta_{\mathrm{s}}\right)$ (Figure $3, B$ ). The same was done at maximal leaflet opening during diastole $\left(\theta_{\mathrm{d}}\right)$ (Figure $3, C$ ). The change in this angle between midsystole and maximal diastolic leaflet opening $\left(\theta_{\mathrm{d}}-\theta_{\mathrm{s}}\right)$ was defined as $\Delta \theta$, and was used to quantify the degree of posterior leaflet mobility.

\section{Statistical Analysis}

Ordinal data (eg, MR grade) are reported as median (interquartile range). Continuous measures (eg, $\mathrm{VCA}, \mathrm{CH}$, leaflet mobility) are reported as mean \pm standard deviation. For ordinal data, comparisons between time points were made using a Friedman repeated-measures analysis of variance (ANOVA) on ranks. If ANOVA yielded a statistically significant result 


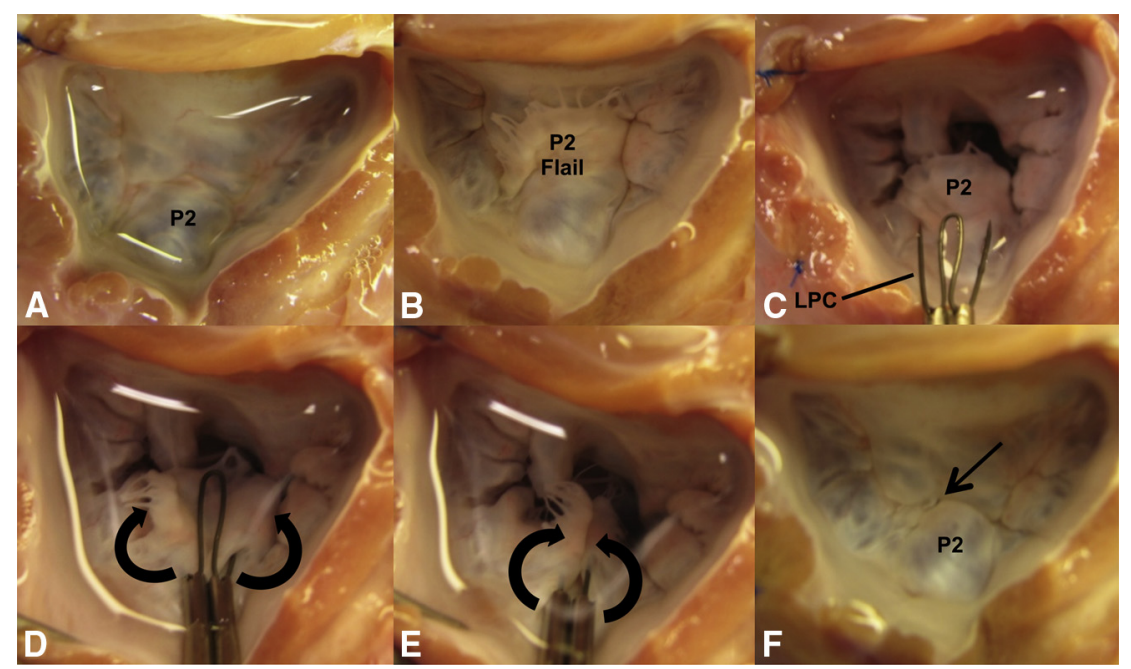

FIGURE 2. En face view of the mitral valve and leaflet plication clip $(L P C)$ placement: left ventricle pressurized in a water-tank setup to test valve competence (A, B, and F). A, Baseline, competent mitral valve with normal P2 segment. B, P2 prolapse/flail created by $1^{\circ}$ and $2^{\circ}$ chordae cutting. C, LPC opened. D, LPC applied to prolapsed P2 segment. E, LPC closed, P2 segment plicated. F, Restored mitral valve competence with elimination of P2 prolapse/flail. Curved arrows indicate the motion of LPC closure and leaflet plication. The straight arrow indicates the hub of the LPC in the final state; the body of the LPC is below the coaptation line in the final resting state.

$(P<.05)$ then a post hoc analysis of ordinal data was accomplished using a Wilcoxon signed ranks test. For continuous variables, a one-way repeatedmeasures ANOVA was done for data that passed the normality and equal variance tests. If ANOVA yielded a statistically significant result $(P<.05)$ then a post hoc test was done using the Bonferroni correction. Interobserver variability for measurements of MR grade and vena contracta area was determined by analysis of 7 randomly selected studies that were reviewed by 2 independent blinded observers. The results were assessed using intraclass correlation coefficients (ICC). Data were analyzed using IBM SPSS Statistics, Version 21.0 (IBM Corp, Armonk, NY).

\section{RESULTS}

\section{Surgical Characteristics and Results}

All animals survived the surgical procedure. After assessing baseline valve competence with cold saline injection, chordae tendineae supporting P2 were cut sequentially starting with the primary marginal chordae supporting the central portion of the P2 free edge. Repeat cold saline injection was then performed to assess valve competence. If the valve was still competent after primary chordae cutting, then secondary chordae supporting the belly of P2 were cut. In all cases, chordae supporting the P1-P2 and P2-P3 junctions were kept intact, thereby creating flail only in the central portion of the $\mathrm{P} 2$ scallop, with chordal support along the P2 margins. Between 2 and 4 primary and secondary chordae were cut in each case. Echocardiographically, the regurgitant jet was directed anteriorly over A2, consistent with the $\mathrm{P} 2$ prolapse/flail that had been created (Figure 4). One animal required an additional CPB run because there was insufficient MR on echocardiography after chordae cutting during the first bypass run. This animal was ultimately left with severe (4+) MR after additional chordae cutting.
One LPC was implanted in each animal. All clip implantations were accomplished without significant tissue trauma (eg, leaflet tears, chordal lacerations). There were no incidents of device embolization, as confirmed by postoperative echocardiograms and direct examination at explant; however, there were 2 cases where the clip moved slightly from the implantation position. In 1 case, the clip seemed to be caught on underlying secondary chordae, which then limited A2-P2 leaflet coaptation. This animal had the lowest baseline $\mathrm{CH}$, which also contributed to the residual MR. In another case, the clip's orientation changed after implantation, shifting to a more oblique position relative to the leaflet hinge point. This led to persistent A2-P2 malcoaptation. There was no evidence of clot formation on or around the device in any of the animals at the time of explant.

\section{LPC Performance}

Median MR grade at baseline was trivial (0-1.5). In 5 of 7 cases, at least moderate-severe MR was created by chordae cutting. In the remaining 2 cases, mild and mild-moderate MR were induced. The median MR grade after chordae cutting was moderate-severe (2.5-4+), which was significantly increased from baseline $(P=.018)$. MR grade decreased significantly after clip placement, with a median MR grade of mild $(0-3+)$ at 2 hours after surgery $(P=.027)$. This final MR grade was not statistically different from baseline $(P=.102)$ (Figure 5, $A)$. The 2 animals found to have improper device position at explant each had moderate (3+) MR 2 hours after clip implantation. This was slightly improved from the moderate-severe (3.5) and severe $(4+)$ MR they had after chordae cutting but before clip implantation. 

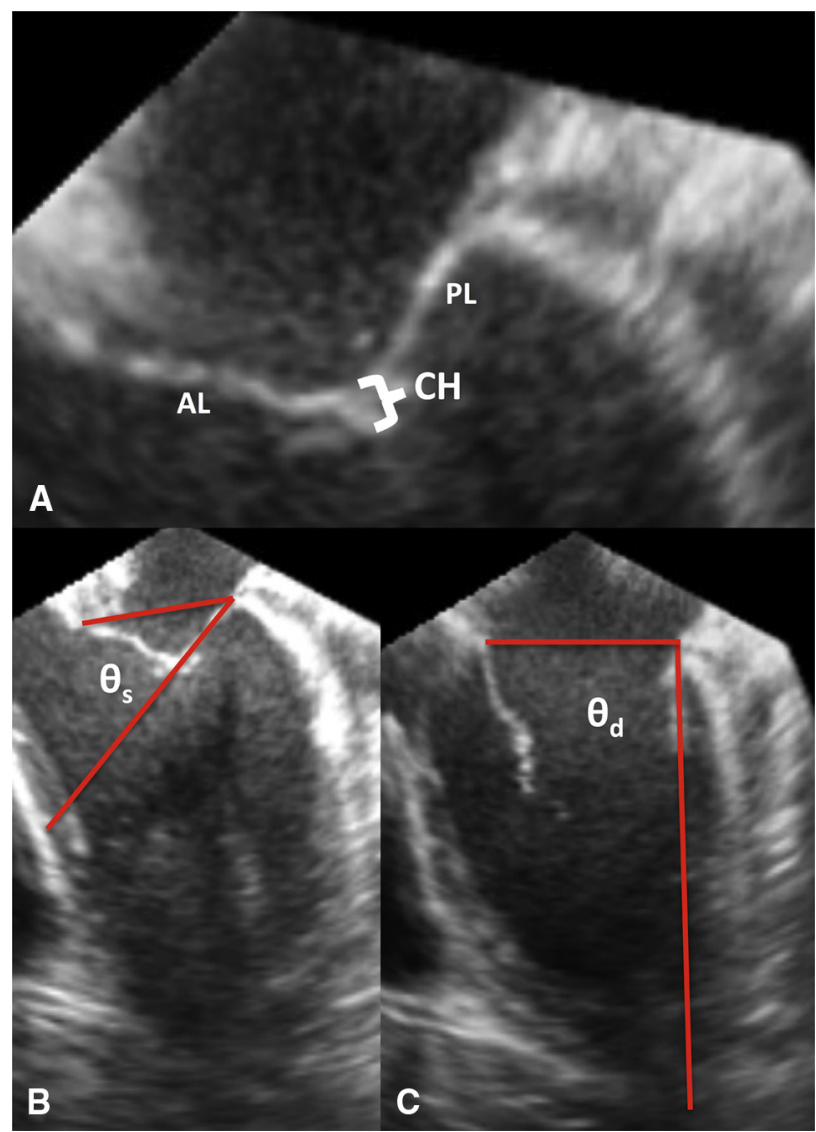

FIGURE 3. Echocardiographic images depicting measurements of coaptation height and posterior mitral leaflet mobility. A, Coaptation height $\mathrm{C} \mathrm{CH}$ ) measured after obtaining the cross-sectional plane in the A2-P2 region during midsystole. $\mathrm{B}, \theta_{\mathrm{s}}$ is the angle between the plane of the mitral annulus and the plane of the $\mathrm{P} 2$ leaflet at midsystole. $\mathrm{C}, \theta_{\mathrm{d}}$ is the angle between the plane of the mitral annulus and the plane of the $\mathrm{P} 2$ leaflet at maximal leaflet opening. $\Delta \theta=\theta_{\mathrm{d}}-\theta_{\mathrm{s}}$ quantifies the degree of posterior leaflet $(P L)$ mobility during the cardiac cycle. $A L$, Anterior leaflet.

VCA tended to increase after chordae cutting and decrease after placement of the LPC; however, these changes were not statistically significant $(F(2,12)=1.791$, $P=.209$ ) (Figure $5, B$ ). In those cases where an optimal functional outcome was attained, the LPC restored coaptation height to baseline: baseline $\mathrm{CH}=0.51 \pm 0.07$ $\mathrm{cm}$ versus $0.44 \pm 0.18 \mathrm{~cm}$ after clip implantation $(P=1.0)$ (Figure $5, C)$. Leaflet mobility was not significantly altered by the LPC: baseline $\Delta \theta=45.8 \pm 4.3^{\circ}$ versus $42.2 \pm 11.0^{\circ}$ after clip implantation $(P=1.0$ ) (Figure $5, D$ ).

\section{Observer Variability}

Excellent correlation was observed in the interobserver variability of echocardiographic measurements. ICC for MR grade was 0.980 (95\% confidence interval [CI], $0.890-0.997)$. ICC for vena contracta area was 0.972 (95\% CI, 0.857-0.995).
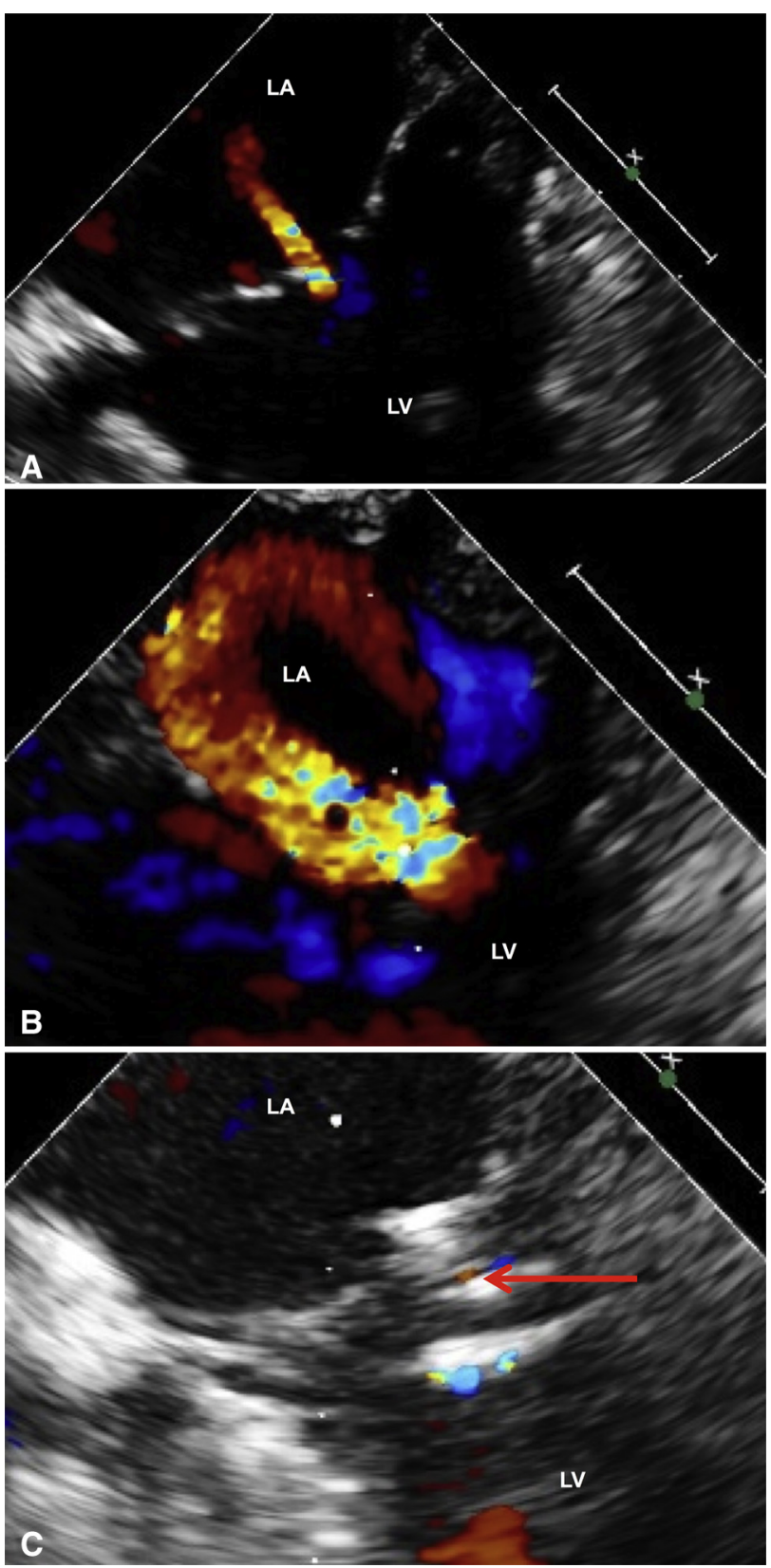

FIGURE 4. 2D color Doppler imaging of MR grade from 1 animal A, Preoperative/baseline trivial-mild MR. B, Severe MR after chordae cutting, with the jet directed over the anterior leaflet consistent with P2 prolapse/flail. C, Restored mitral valve competence after leaflet plication clip implantation. Red arrow indicates the leaflet plication clip (note shadow imaging artifacts above and below the clip. LA, Left atrium; $L V$, left ventricle.

\section{DISCUSSION}

The clinical sequelae of MR are well known and surgical repair is widely accepted. ${ }^{17}$ Conventional surgical repair techniques have dramatically improved over the past several decades and current surgical outcomes are excellent. ${ }^{8,9,18}$ There remains, however, a cohort of patients 

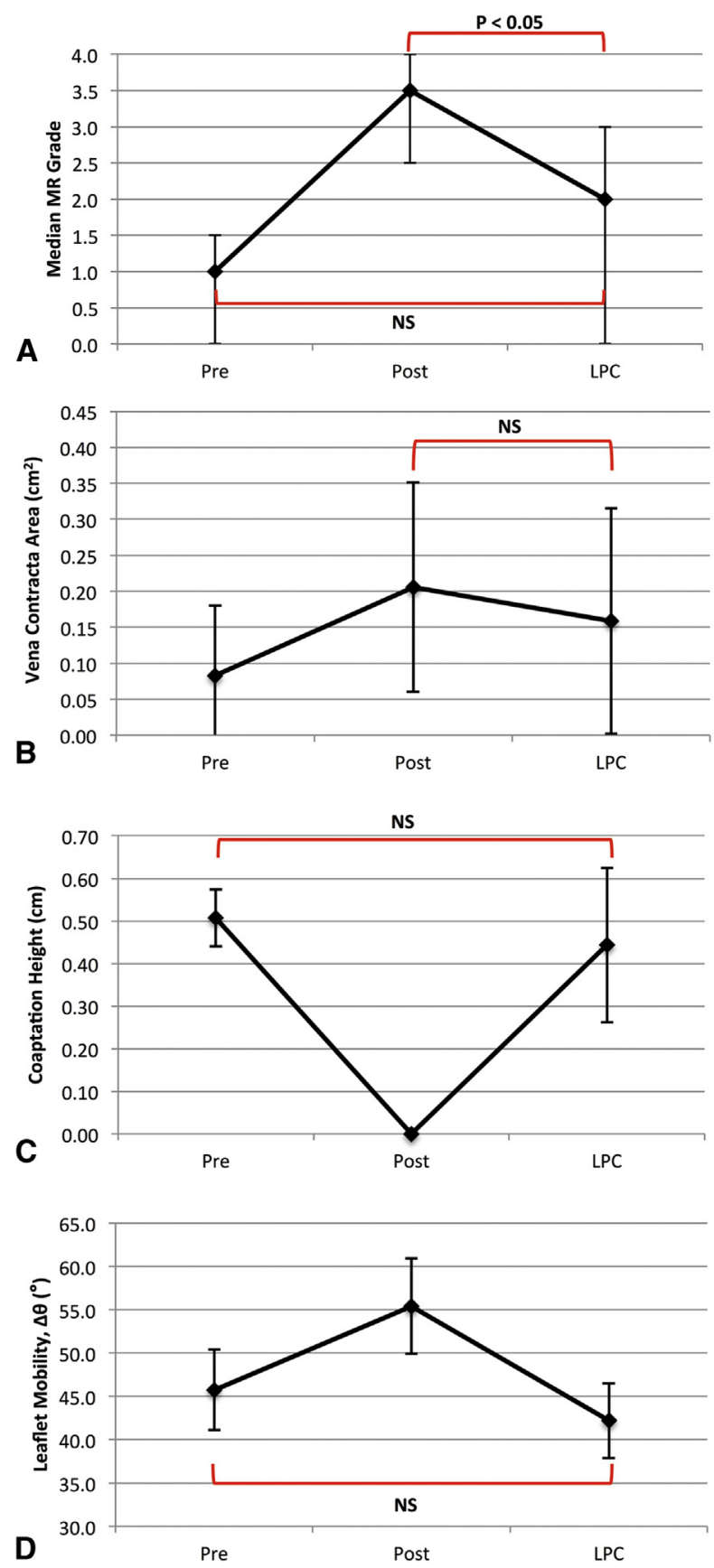

FIGURE 5. Longitudinal data for MR grade, vena contracta area, coaptation height, and posterior mitral leaflet mobility. A, Median MR grade; implantation of the leaflet plication clip (LPC) resulted in a statistically significant decrease in MR grade; the final MR grade was similar to the baseline MR grade. B, Vena contracta area tended to increase after chordae cutting and decreased after LPC implantation. C, Coaptation height was restored to baseline by the LPC. D, Posterior mitral leaflet mobility was not significantly altered by the LPC. For MR grade, data are presented as the median, error bars indicate the interquartile range. For vena contracta area, coaptation height, and leaflet mobility, data are presented as means, error bars indicate standard deviation. Pre, Preoperative; Post, post-MR creation; NS, not significant; $M R$, mitral regurgitation. whose operative risk precludes conventional heart surgery. ${ }^{19}$ For these high-risk patients, emerging minimally invasive and beating-heart mitral valve repair techniques and technology offer an important alternative.

For myxomatous disease, in particular, use of the MitraClip as well as chordal replacement devices have been described. The MitraFlex (TransCardiac Therapeutics LLC, Atlanta, Ga) and the NeoChord (NeoChord, Inc., Minnetonka, Minn) use a transapical approach for artificial chordae implantation. ${ }^{20}$ The Babic device uses a combined transapical and transseptal approach for chordae implantation. $^{21}$

The novel device presented in this article aims to broaden the scope and enhance the effectiveness of minimally invasive MVP repair by enabling an alternative method of leaflet repair: leaflet plication. The novel LPC selectively folds the prolapsed leaflet segment without involving the adjacent, normal leaflet tissue, as is required with edge-toedge repair techniques. The present study is the first to test the LPC in vivo. It was conducted under open surgical conditions to specifically assess the clip's performance without the confounding effect of experimental imageguided and/or minimally invasive LPC deployment methods. This study demonstrated that the LPC can successfully restore leaflet coaptation and valve competence by functionally excluding the prolapsed leaflet segment. Moreover, because of the LPC's low profile, normal valve dynamics (eg, leaflet mobility) are preserved. The clip's low profile also minimizes thrombogenicity because most of the device is covered by leaflet tissue. Thus, the LPC could make minimally invasive folding mitral valvuloplasties more feasible and reproducible.

In this initial in vivo study, there was some variation in device performance. Although all animals experienced statistically significant improvement in MR grade after clip placement, 3 animals were left with moderate MR and 4 were left with zero to mild MR. The possible mechanisms underlying the 3 suboptimal outcomes relate to: (1) preoperative valve characteristics and (2) device implantation/function.

\section{Preoperative Valve Characteristics}

Baseline leaflet coaptation seemed to influence device performance; animals with minimal A2-P2 coaptation preoperatively tended to have suboptimal results. Animals with significant baseline coaptation had more successful repairs. This finding is likely related to one of the limitations in the MR creation model. By cutting chordae supporting the central portion of $\mathrm{P} 2$, this model successfully created P2 segment flail; however, this does not perfectly mimic leaflet prolapse. Moreover, this model did not reproduce the characteristics of a degenerative/myxomatous mitral valve, with excessive/redundant valve tissue. ${ }^{22}$ Consequently, in animals with minimal baseline coaptation, 
P2 plication may have excessively reduced the posterior leaflet surface area to the point where valve competence was impaired. The current study did not have sufficient imaging acquisition to assess leaflet surface area and quantitatively analyze its effect on device performance. It is possible that a minimum leaflet surface area to valve orifice area ratio exists that is required for the clip to be successful. This is the focus of future work.

\section{Device Implantation and Function}

In 2 of the 3 animals left with moderate MR, clip implantation and function were suboptimal. In 1 case, direct examination on explant revealed that the LPC was caught on underlying secondary chordae. Because the device punctures the leaflet belly and passes along the ventricular surface of the leaflet, it is crucial to ensure that the clip arms do not catch underlying secondary and/or strut chordae. This is accomplished by gently grasping the $\mathrm{P} 2$ scallop from the anterior and posterior points of its free edge, suspending it away from the underlying ventricular endocardial surface, and flattening it out during implantation. As the clip is advanced into the leaflet, it is kept parallel to the leaflet plane to avoid entangling underlying structures. These important details of device implantation will be incorporated into future design iterations that target beating-heart implantation.

In the case where the LPC shifted obliquely after implantation, it is likely that the clip was not implanted perpendicular to the annulus, and that subsequent intracardiac forces acted asymmetrically on the clip, pushing it into an oblique position. When the clip lies obliquely, it pulls the P2 leaflet tissue away from the coaptation line, thereby preventing P2-A2 coaptation. This underscores the importance of the clip being oriented perpendicular to the leaflet hinge point at the time of implantation. Current work is focusing on a more advanced locking system for the clip, which will provide even greater fixation to the leaflet tissue and prevent clip migration.

A concurrent reduction annuloplasty was not performed. Annuloplasty was excluded in an effort to analyze the effect of the LPC in isolation. Furthermore, leaflet flail was created only in the central portion of $\mathrm{P} 2$ to avoid excessive leaflet plication, which might distort annular geometry and necessitate a sliding annuloplasty. Future work will address the effectiveness of the LPC when a concurrent annuloplasty is performed, as this may further improve the functional outcome after clip implantation. This will be particularly relevant given the development of transcatheter mitral annuloplasty devices that could ultimately be used in conjunction with the LPC. ${ }^{23}$

The ultimate goal is to achieve leaflet plication and MVP repair by using beating-heart, image-guided clip implantation techniques. However, it should be recognized that the LPC has potential applications outside minimally invasive or beating-heart mitral valve repair. The clip's simple and reproducible plication of the prolapsed leaflet segment makes it an attractive alternative in conventional heart surgery, which often entails complex leaflet repairs. Moreover, the reversibility of the clip allows the surgeon to remove and reposition the clip if intraoperative valve testing demonstrates a suboptimal result. This reversibility gives the surgeon greater versatility and flexibility compared with conventional, suture-based leaflet resection techniques.

The present study is limited to a short-term evaluation of the performance of the LPC for treating MVP. Chronic in vivo studies are necessary to assess the long-term performance of the device. In particular, evidence of device migration and the local tissue response to the LPC will be assessed. Future studies will also focus on valve anatomy to determine the anatomic characteristics that lead to optimal device performance. For example, understanding the maximum width of prolapse/flail that can be treated with the LPC will be important for determining anatomic indications and contraindications to its use. Also, determining whether other segments of leaflet prolapse (eg, P1, P3, anterior leaflet) can be treated with this clip will be important.

In conclusion, this initial in vivo study demonstrates that the LPC can effectively repair MVP in an animal model by restoring normal coaptation without compromising leaflet mobility. This technique and device have important applications in a wide range of mitral valve therapies, including conventional heart surgery, minimally invasive mitral valve surgery, and image-guided beating-heart interventions. These are early results, and there are imperfections in the current device design that require further development. Critical to the next steps is a chronic animal model to better characterize longer-term device behavior. In addition, future work will focus on specific anatomic indications/contraindications, and developing beating-heart methods of implantation. Accomplishing this would broaden our technical armamentarium for mitral valve repair and enhance our ability to repair MVP/MR in high-risk surgical patients.

The authors are grateful to the Animal Research Children's Hospital staff (Arthur Nedder, DVM, and veterinary technicians) and the Boston Children's Hospital perfusion team for their overwhelming support and assistance in this project.

\footnotetext{
References

1. Filsoufi F, Carpentier A. Principles of reconstructive surgery in degenerative mitral valve disease. Semin Thorac Cardiovasc Surg. 2007;19: 103-10.

2. Gillinov MA, Cosgrove DM, Blackstone EH, Diaz R, Arnold JH, Lytle BW, et al. Durability of mitral valve repair for degenerative disease. J Thorac Cardiovasc Surg. 1998;116:734-43.

3. Carpentier A. Cardiac valve surgery-the "French correction." J Thorac Cardiovasc Surg. 1983;86:322-37.
} 
4. Calafiore AM, Di Mauro M, Actis-Dato G, Iaco AL, Centofanti P, Forsennati P, et al. Longitudinal plication of the posterior leaflet in myxomatous disease of the mitral valve. Ann Thorac Surg. 2006;81:1909-10.

5. Mihaljevic T, Blackstone EH, Lytle BW. Folding valvuloplasty without leaflet resection: simplified method for mitral valve repair. Ann Thorac Surg. 2006; 82:e46-8.

6. Woo YJ, MacArthur JW. Simplified nonresectional leaflet remodeling mitral valve repair for degenerative mitral regurgitation. J Thorac Cardiovasc Surg. 2012;143:749-53.

7. Tsukui H, Umehara N, Saito H, Saito S, Yamazaki K. Early outcome of folding mitral valve repair technique without resection for mitral valve prolapse in 60 patients. J Thorac Cardiovasc Surg. 2013;145:104-8.

8. DeBardino DJ, ElBardissi AW, McClure RS, Razo-Vasquez OA, Kelly NE, Cohn LH. Four decades of experience with mitral valve repair: analysis of differential indications, technical evolution, and long-term outcome. J Thorac Cardiovasc Surg. 2010;139:76-84.

9. Lawrie GM, Earle EA, Earle N. Intermediate-term results of a nonresectional dynamic repair technique in 662 patients with mitral valve prolapse and mitral regurgitation. J Thorac Cardiovasc Surg. 2011;141:368-76.

10. Elahi M, Asopa S, Pflueger A, Hakim N, Matata B. Acute kidney injury following cardiac surgery: impact of early versus late haemofiltration on morbidity and mortality. Eur J Cardiothorac Surg. 2009;35:854-63.

11. Dong G, Liu C, Jing H, Li D, Wu H. Postoperative abdominal complications after cardiopulmonary bypass. J Cardiothorac Surg. 2012;7:1-5.

12. Carrascal Y, Guerrero AL. Neurological damage related to cardiac surgery: pathophysiology, diagnostic tools and prevention strategies. Using actual knowledge for planning the future. Neurologist. 2010;16:152-64.

13. Mirabel M, Iung B, Baron G, Messik-Zeitoun D, Detaint D, Vanoverschelde JL, et al. What are the characteristics of patients with severe, symptomatic, mitral regurgitation who are denied surgery? Eur Heart J. 2007;28:1358-65.

14. Chiam PTL, Ruiz CE. Percutaneous transcatheter mitral valve repair: a classification of the technology. JACC Cardiovasc Interv. 2011;4:1-13.

15. Matte GS, del Nido PJ. History and use of del Nido cardioplegia solution at Boston Children's Hospital. J Extra Corpor Technol. 2012;44:98-103.

16. Kahlert P, Plicht B, Schenk IM, Janosi R-A, Erbel R, Buck T. Direct assessment of size and shape of noncircular vena contracta area in functional versus organic mitral regurgitation using real-time three-dimensional echocardiography. J Am Soc Echocardiogr. 2008;21:912-21.

17. Enriquez-Sarano M, Akins CW, Vahanian A. Mitral regurgitation. Lancet. 2009; 373:1382-94.

18. David TE, Omran A, Armstrong S, Sun Z, Ivanov J. Long-term results of mitral valve repair for myxomatous disease with and without chordal replacement with expanded polytetrafluoroethylene sutures. J Thorac Cardiovasc Surg. 1998;115: 1279-86.

19. Vahanian A, Lung B, Himbert D, Nataf P. Changing demographics of valvular heart disease and impact on surgical and transcatheter valve therapies. Int J Cardiovasc Imaging. 2011;27:1115-22.

20. Seeburger J, Leontjev S, Neumuth M, Noack T, Hobartner M, Misfeld M, et al. Trans-apical beating-heart implantation of neo-chordae to mitral valve leaflets: results of an acute animal study. Eur J Cardiothorac Surg. 2012;41:173-6.

21. Panic G, Ristic M, Putnik S, Markovic D, Divac I, Babic UU. A novel technique for treatment of mitral valve prolapse/flail. J Thorac Cardiovasc Surg. 2009;137: 1568-70.

22. Albacker TB, Gillinov M, Mihaljevic T. Mitral valve repair techniques for anterior and posterior leaflets. In: Franco KL, Thourani VH, eds. Cardiothoracic Surgery Review. New York: Lippincott Williams \& Wilkins; 2012:382-7.

23. Perlowksi A, St Goar F, Glower DG, Feldman T. Percutaneous therapies for mitral regurgitation. Curr Probl Cardiol. 2012;37:42-68.

\section{Discussion}

Dr Valavanur Subramanian (New York, NY). Very elegant. I have a few questions. How do you adjust your amount of folding into your clip or do you have different sizes, number one?

Dr Feins. We have multiple clip sizes that we use. For the purposes of this in vivo study, we found that almost all animals except 1 required just the smallest size clip we have, which I can back up to show you based on the scale from my slides. One animal did require a larger clip.

The clips themselves are fairly fixed in the amount of leaflet tissue that they can plicate, which you can see is probably defined by the maximum opening state of the clip itself. However, it is a fairly trivial matter to create variable size clips for the purposes of plicating different amounts of leaflet tissue.

Dr Subramanian. In the animals, do you look at the flailed gap, how much of a flailed gap you had before you had a successful clip deployment?

Dr Feins. I'm sorry, could you repeat the question?

Dr Subramanian. The flailed gap, how much of a prolapse from the annular plane, because there are limitations there.

Dr Feins. What we had tried to do was maintain the chordae that were supporting the segments of the leaflet between the P2 and P3 scallops and the P1 and P2 scallops, with the goal of having some leaflet tissue of P2 that still had chordal support so that when we plicated the central segment we would have some supporting leaflet tissue to maintain valve function.

Generally speaking, our goal was to create prolapse in just the central portion of $\mathrm{P} 2$, which essentially was about 3 or $4 \mathrm{~mm}$. I would say between 3 and $5 \mathrm{~mm}$ in terms of the length of the coaptation line for the valve itself.

Dr Song Wan (Shatin, Hong Kong). Congratulations for this innovative design and excellent experimental result. I have one comment and one question. The comment is, your idea appears to me to be more advanced than MitraClip, however, it didn't overcome the intrinsic critical drawback of MitraClip, namely, it only addresses the leaflet but not the annulus, and without proper annuloplasty, the long-term durability is reduced, as all of us know already.

The question is, your device seems more suitable for the chronic, for example, P2 prolapse, with excessive valve tissue and maybe myxomatous change. However, your animal model is an acute model with chordal cutting, and the leaflets are more or less normal in this setting. Do you think your device can be used in acute MR, like a sudden rupture of the chordae, exactly mimic your animal model?

Dr Feins. Thank you for your comments and question. I certainly think that there is some limitation to our animal model with regard to the type of lesion that we were creating. Not all prolapses are created equal, and this is a very different lesion than a myxomatous valve with excessive leaflet tissue. This is a limitation of our model. You could envision various scenarios where you would create a more clinically similar type of lesion, and that may involve augmentation of the leaflet and then surviving animals to create a dilated annulus that mimics the clinical scenario.

The purposes of this study were mainly to assess the clip in an acute setting, not because this would necessarily be a replacement to a chordal replacement, for example, but simply as a way of seeing if the ex vivo findings that we had could be reproducible in an acute model. And I suspect in the setting of what you are describing, which is excessive leaflet tissue with redundancy, which we see in a more chronic setting, that this leaflet plication clip would arguably have even better results than in an acute chordal rupture model.

And just in response to your comment, I completely agree. Our intention for not including an annuloplasty was simply to assess 
the sole effect of the clip in isolation. I think we can all agree that an annuloplasty in addition will improve outcomes. And while the clip doesn't add an annuloplasty, and in that way is not an improvement on the current MitraClip, I think it is fair to say that one of the reasons that mitral valve reparative surgery has improved over the past several decades is due to the breadth of reparative techniques we have: annuloplasty, edge-to-edge repair, and the various ways to address the leaflet and the chordae. This represents one way of doing that by plicating the leaflet rather than simply involving the other leaflet segments.
Dr Mathew Williams (New York, NY). What are your plans for putting this in a catheter-based approach?

Dr Feins. We are currently developing some of the minimally invasive methods for implanting this, and there is a wide range of applications. I think when we developed this, we saw this not just as a percutaneous or catheter-based technique. There are also transcardiac ways of implanting it, as well as implantation in the open heart. One could argue that in conventional heart surgery, having a device such as this allows for a more reproducible way of plicating the leaflet instead of suture-based techniques. 